\section{Darwin, Freud and creationism}

SIR-I would like to comment on Anthony Clare's approbatory review ( $\mathrm{Na}$ ture 318, 112; 1985) of a number of books purporting to dispose once and for all of Freud's pretensions as a scientist, by drawing a comparison with the creationists who would have us abandon Darwin's contributions to biology. Neither Darwin nor Freud would have claimed in their time that their subjects had reached what Kant called the sure path of a science (though it could be thought that molecular biology has more recently provided the intellectual key to an adequate theory of evolution); but to dismiss Freud's attempt to grasp the nature of the problem presented to us by human behaviour and its aberrations because, like Darwin, he needed to substitute metaphor for mechanism in his preliminary sketch of what might become a rational psychology, is to throw out the baby in order to play with the bath water. If psychoanalysis is to be regarded as of no account, what kind of psychiatry are we to be left with? And if what we are left with is all we are going to get, how are we to respect its protagonists as critical scientists when they are content with so unsatisfactory an amalgam of empiric treatments and shaky statistics (the latter useful as a screening test to disprove some tentative hypotheses but unable, for reasons that Karl Popper has given us, to generate alternative ones) as the basis for their surely not very satisfactory practice? As Sir George Pickering (no friend to analysis) once said to me, an ounce of honest if mistaken endeavour to understand a problem is worth a ton of destructive criticism; for truth remains the child of error, not confusion.

John A. Davis University of Cambridge Clinical School, Department of Paediatrics, Level 8, Addenbrooke's Hospital, Hills Road, Cambridge CB2 2QQ, UK

\section{PhD theses}

SiR-P. A. Lund (Nature 317, 470; 1985) writes about the "labour pains involved in the production ... [ [ of a] $\mathrm{PhD}$ thesis". The major problems in most of the graduate schools that I have been associated with in Europe, Canada and the United States are: (1) the production of trivial PhDs; (2) the "bogging down" of many $\mathrm{PhD}$ students by insurmountable experimental or theoretical difficulties; (3) the virtual abandonment of some PhD students, or in many cases lack of communication, between them and their supervisors.

At the Feinberg Graduate School of this institute (where we have some $500 \mathrm{MSc}$ and $\mathrm{PhD}$ students), we inititated a system many years ago (see D. Samuel Pure and Applied Chem. 22, 163; 1970) for raising the standard of PhDs and improving the quality of supervision. Within a year of being admitted, each PhD student must submit a detailed written research proposal, based on his reading of the published literature on the subject and preliminary laboratory work or calculations - in effect, a "feasibility study". This proposal is then sent to two senior members of the staff, not necessarily precisely in the same field, who interview the student and determine his overall knowledge, and his ability to undertake the proposed research project and complete it in a reasonable time.

The staff members continue to see the student and periodic reports, throughout his or her time at the institute. In spite of some initial opposition to this scheme, on the grounds of restricting the "academic freedom" of the supervisor, as well as the time involved in following the career of each student, it has worked extremely well for over twenty years. Apart from raising the standard of PhDs and solving both scientific and personal problems, it has frequently helped in the research itself by encouraging an exchange of ideas between different research groups and departments. This scheme, and variations of it, are used in other institutes and universities but not widely in the United Kingdom. I would suggest that it be adopted more extensively in order to protect and encourage that very precious commodity, the graduate student, as well as producing, perhaps, better research.

SAMUEL

Weizmann Institute of Science,

(Viscount Samuel)

Rehovot,

Israel

SIR-Recent correspondence in Nature on the value of $\mathrm{PhD}$ theses suggests to me that many scientists do not realize that such theses are in fact readily available through university libraries. One important source is the thesis filming operation at the British Library Lending Division at Leamington Spa. In 1984-85, the British Library Lending Division's total expenditure for literature was more than $£ 3,600,000$ of which $£ 86,000$ was spent on dissertations. With the exception of London and the Council for National Academic Awards, all British universities submit their doctoral theses for copying. The British Library Lending Division holds 1,410 miles of roll microfilm. In 1984-85, 5,500 theses were filmed. Theses are sold through the British Library Lending Division by filling in a Thesis Declaration Form. Theses can be supplied on microfilm, photocopy or microfiche. On the whole, masters theses are not collected. The division buys, on demand, doctoral dissertations listed in Dissertation Abstracts International which are part of the University Microfilms doctoral programme. Various indexes are available for identifying theses, including Dissertation Abstracts International, British Reports, Translations and Theses, and Aslib's Annual Index to Theses Accepted for Higher Degrees by the Universities of Great Britain and Northern Ireland and the Council for National Academic Awards.

Sheila M. Mould (Librarian)

MRC Clinical and Population

Cytogenetics Unit,

Western General Hospital,

Edinburgh, EH4 $2 \mathrm{XU}, \mathrm{UK}$

\section{Neptune's rings}

SIR-Your leading article "Whose rings around Neptune?" (Nature 318, 505; 1985 ) contains some errors. First, proper credit for the observations made at Cerro Tololo would mention that I was the visiting astronomer who made the observation of the occultation by the ring arc, with the assistance of L.R. Elicer (whose help greatly streamlined the observing procedure). Second, the observations were not made "in some haste" as stated. We observed both the star and planet on the night of 21 July with different filters in order to select three filters that would give good signal-to-noise across a broad spectral range using the $0.9-\mathrm{m}$ three channel photometer. I chose to use the Johnson U $(0.44 \mu \mathrm{m})$, Johnson $\mathrm{V}(0.55 \mu \mathrm{m})$ and an infrared $(0.87 \mu \mathrm{m})$ filters. Both the Johnson $U$ and IR filters were internally mounted in the photometer. The Johnson $\mathrm{V}$ filter was mounted in a movable filter slide with a handle extending from the photometer very near to where the astronomer is positioned to guide the telescope. We suspect that one of us knocked the slide so that the occultation was observed through another filter, linear combination of filters or combination of filter and open sky, as the counts did not correspond to the test of the visual wavelength filter counts we conducted at the beginning of the night on 22 July.

Finally, Lissauer's article could have referred to an abstract in the Lunar and Planetary Conference XVI, p. 368,1985 , which includes all of the scientists involved and all of the data combined together. (Although I understand that Manfroid and Haefner requested that their names and data be withdrawn from the abstract, the volume of abstracts had already been printed when this request was made.)

I would like to add that William Hubbard and I have continued a productive and cooperative affiliation with the French astronomers for subsequent observations of occultations by the Neptune system. FaITH VILAS NASA, Lyndon B. Johnson Space Center, Houston, Texas 77058, USA 